\title{
Thermophysical Properties of Liquid Silver-Bismuth-Tin Alloys
}

\author{
Yu. Plevachuk, V. Sklyarchuk, A. Yakymovych, P. Svec, D. Janickovic, and E. Illekova
}

(Submitted October 21, 2011; in revised form January 4, 2012)

\begin{abstract}
Tin-bismuth-silver alloys are under intense consideration as favorable lead-free solders for consumer electronics and telecommunications. The investigated samples of Ag-Bi10-Sn with Ag content from 3.33 to 10 at.\% were prepared both in the traditional bulk form and in the ribbon form by the rapid solidification technique. The electrical conductivity and thermal conductivity, thermoelectric power and viscosity studies were carried out in a wide temperature range above the liquidus. Corresponding fit relations have been derived.
\end{abstract}

Keywords electronic properties, metals and alloys, rapid solidification, phase transitions, ribbons, solder foil

\section{Introduction}

On implementation of the EU RoHS and WEEE directives (Ref 1) extensive investigations have been carried out to find lead-free alloys instead of traditional $\mathrm{Sn}-\mathrm{Pb}$ solders. If a progress has been made in the area of low-temperature lead-free solders (see for example COST-531 (Ref 2), research is seriously lacking in replacements for high-temperature $\mathrm{Sn}-\mathrm{Pb}$ solder alloys, where the lead contents can be above 85 wt.\%. High-temperature solders with melting temperatures above $550 \mathrm{~K}$ are widely used in the electronics industry for advanced packing technologies (Ref 3, 4).

The $\mathrm{Ag}_{4.7} \mathrm{Bi}_{95.3}$ eutectic alloy exhibits an acceptable melting point $(535.5 \mathrm{~K})$, has hardness similar to that of $\mathrm{Pb}-5 \mathrm{Sn}$ (wt.\%), and affordable cost. Thus, it has been suggested as a die attach solder for power devices and light-emitting diode (LED). The development of Ag-Bi solder alloys is still ongoing mainly due to their inferior thermal and electrical conductivity as well as poor workability (Ref 5).

As the number of binary alloys for high-temperature solders is rather limited, higher-component systems provide an opportunity

This article is an invited submission to JMEP selected from presentations at the Symposia "Wetting, soldering and brazing" and "Diffusion bonding and characterization" belonging to the Topic "Joining" at the European Congress and Exhibition on Advanced Materials and Processes (EUROMAT 2011), held September 12-15, 2011, in Montpellier, France, and has been expanded from the original presentation.

Yu. Plevachuk, V. Sklyarchuk, and A. Yakymovych, Department of Metal Physics, Ivan Franko National University, 79005 Lviv, Ukraine; and P. Svec, Institute of Physics, Slovak Academy of Sciences, 84511 Bratislava, Slovakia; and Faculty of Materials Science and Technology, Slovak University of Technology, Trnava, Slovakia; and D. Janickovic and E. Illekova, Institute of Physics, Slovak Academy of Sciences, 84511 Bratislava, Slovakia Contact e-mail: plevachuk@mail.lviv.ua to engineer alloys with desired physical and mechanical properties. It has been reported that $\mathrm{Bi}$ additions to Ag-Sn alloys improve wetting and spreading performance (Ref 6, 7). At the same time, small additions of a third element such as $\mathrm{Ag}$ (of about $2 \mathrm{wt} . \%$ ) to the Bi-Sn alloys can considerably improve its fatigue life (e.g., see (Ref 8$)$ and references therein). Therefore, a ternary Ag-Bi-Sn system looks to be very promising for the hightemperature soldering ( Ref 5-7).

The development of lead-free solders requires a clear and thorough understanding of their structural properties on the basis of sufficient and reliable thermophysical data. The increasing influence of computational modeling in all technological processes generates an increased demand for accurate values of the physical properties of the materials involved, which are used as fundamental inputs for each model. The solidification process of a liquid alloy has a profound impact on the structure and properties of the solid material. Therefore, knowledge of the thermophysical properties of the molten alloys prior to solidification becomes very important for the development of materials with required characteristics. In this work, the thermophysical properties (electrical conductivity, thermoelectric power, viscosity, thermal conductivity) of the $\mathrm{Ag}-\mathrm{Bi}-\mathrm{Sn}$ alloys with high content of $\mathrm{Sn}$ have been investigated over a wide temperature range from 300 up to $1000 \mathrm{~K}$.

\section{Experimental Details}

One of the targets of this work is to study and compare properties of selected alloys prepared both in the traditional bulk form and in the ribbon form by the rapid solidification technique. The shape of thin foil or ribbon is convenient for joining of large areas with well-defined joint dimensions, perspectively for joining the metallic matrix composites. The Ag-10Bi-Sn alloys were prepared by melting appropriate amounts of the relevant metals, with $4 \mathrm{~N}+$ purity in an induction furnace filled with $4 \mathrm{~N} 6$ pure argon at approximately $600{ }^{\circ} \mathrm{C}$. The samples in the form of metallic ribbon $(6 \mathrm{~mm}$ wide and $20-30 \mu \mathrm{m}$ thick) were prepared by the method of planar flow casting in air with quenching rate of about $10^{6} \mathrm{~K} \mathrm{~s}^{-1}$. 
The electrical conductivity, $\sigma(T)$; thermoelectric power, $S(T)$; thermal conductivity, $\lambda(T)$; and viscosity, $\eta(T)$, measurements were carried out on the five $\mathrm{Sn}$-based $\mathrm{Ag}-\mathrm{Bi}-\mathrm{Sn}$ alloys $\left(\mathrm{Ag}_{3.33} \mathrm{Bi}_{10} \mathrm{Sn}_{86.67}, \quad \mathrm{Ag}_{4.67} \mathrm{Bi}_{10} \mathrm{Sn}_{85.33}, \quad \mathrm{Ag}_{6.67} \mathrm{Bi}_{10} \mathrm{Sn}_{83.33}\right.$, $\mathrm{Ag}_{8.33} \mathrm{Bi}_{10} \mathrm{Sn}_{81.67}$, and $\mathrm{Ag}_{10} \mathrm{Bi}_{10} \mathrm{Sn}_{80}$, all in at.\%). The results for some selected melts are shown in Fig. 1, 2, 3, and 4. The measured properties of other compositions revealed similar behavior.

\subsection{Electrical Conductivity and Thermoelectric Power Measurements}

Two 4-point method experimental facilities were used for electrical conductivity measurements. The experiments were performed in an argon atmosphere. Graphite electrodes for current and potential measurements were placed in the wall of the vertical cylindrical $\mathrm{BN}$-ceramic measuring cell along its vertical axis. The potential electrodes were provided with thermocouples for temperature measurements. Single thermoelectrodes of these thermocouples were used for electrical conductivity and thermoelectric power determination. The melt temperature was measured by WRe-5/20 thermocouples in close contact with the liquid. The cell construction permits to carry out the electrical conductivity and thermoelectric power measurements simultaneously in one run. For further details of this method and its experimental realization we refer to (Ref 9). The resultant error of the electrical conductivity measurements is about 2 and $5 \%$ for the thermoelectric power determination.

In the course of the conductivity measurements of the solid ribbons, the main difficulty was connected with determination of the ribbon cross-section, which was not fully uniform. For this reason, density of the solid sample has been determined by using the Archimedes principle at room temperature. Knowing the length, width, and mass of the ribbon sample, the volume and later the effective cross-section were determined. Finally, temperature dependence of the absolute electrical conductivity was found. Each composition was measured several times to get reliable data.

\subsection{Thermal Conductivity Measurements}

An experimental arrangement based on the steady-state concentric cylinder method was used for thermal conductivity measurements (Ref 10). The apparatus comprises two coaxial cylinders (stainless steel, boron nitride- $\mathrm{BN}$ or graphite) separated by a gap, into which the melt is poured. A central hole is drilled in the inner cylinder for an internal heater made of a molybdenum wire, wound on an alumina form. The inner

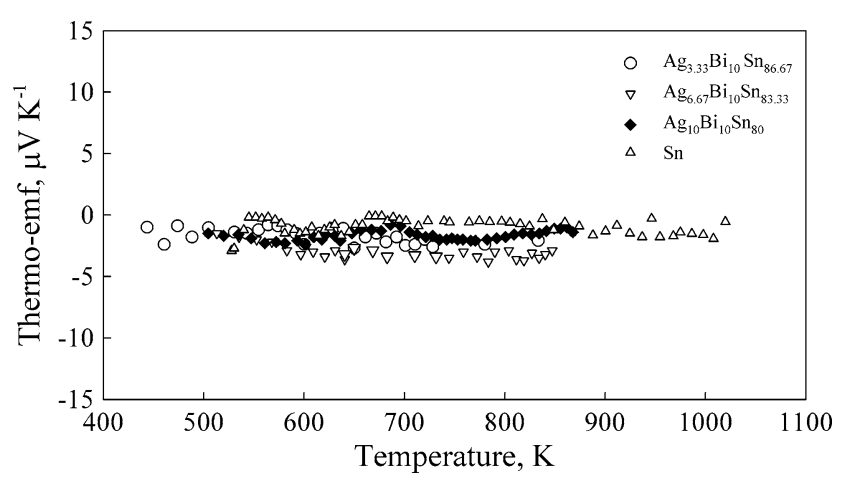

Fig. 2 Thermoelectric power of liquid Ag-Bi-Sn alloys as a function of temperature

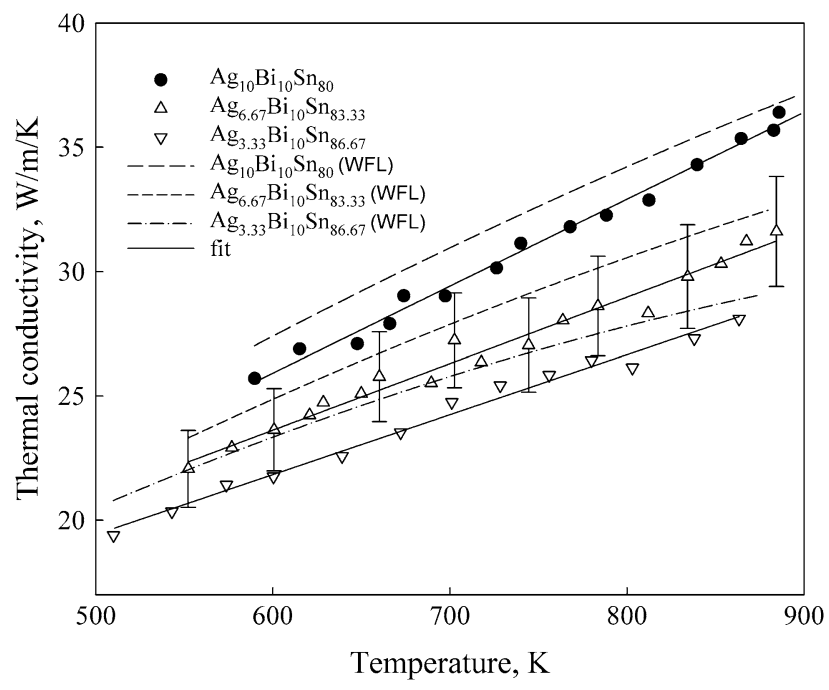

Fig. 3 Thermal conductivity of liquid Ag-Bi-Sn alloys as a function of temperature

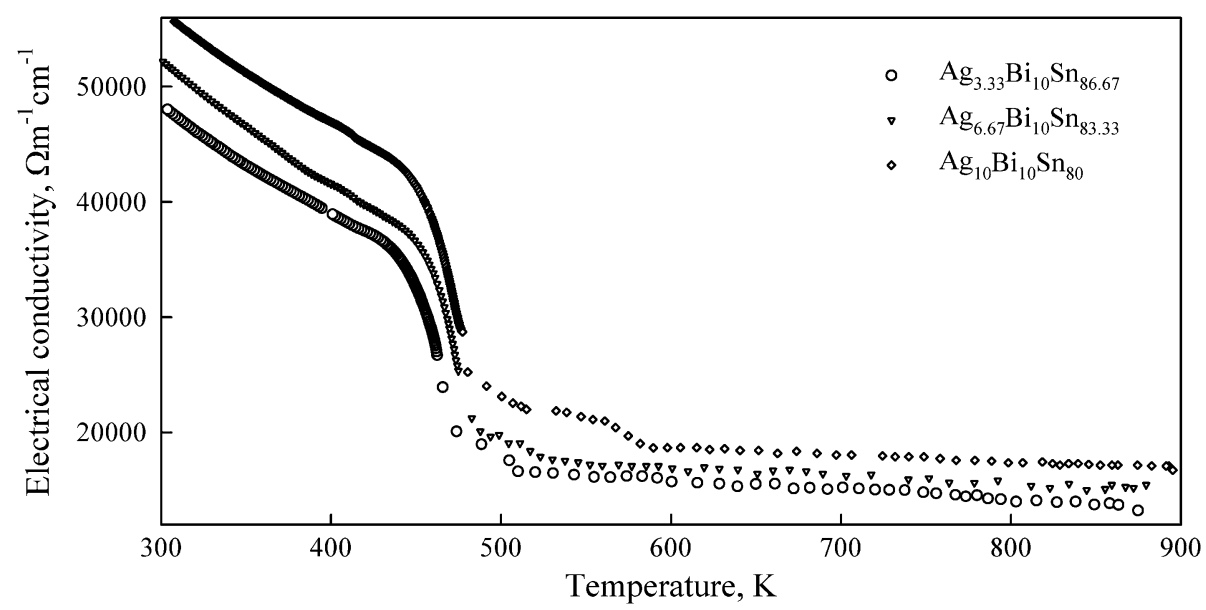

Fig. 1 Electrical conductivity as a function of temperature for Ag-Bi-Sn alloys in the solid ribbons and liquid bulks 
heater is used for producing the necessary temperature gradient in the investigated melt layer. The cell is closed by a BN cover, which is sealed with a special compound based on a finely dispersed $\mathrm{BN}$ powder. The outer three-section furnace is made of molybdenum wire wound on a $\mathrm{BN}$ form. The outer heater produces an overall temperature level, and its upper and lower sections permit regulation of the temperature field over the height of the apparatus. Tungsten-rhenium WR5/20 thermocouples were used in the experiments. Two thermocouples placed in the body of the inner cylinder allow the examination of the temperature distribution over the radius of the apparatus. The coefficient of thermal conductivity can be calculated from the formula for the heat transfer in a cylindrical layer. The design of the apparatus assures a maximum reduction of the heat leakage and of convection. The resultant error of the thermal conductivity measurements is about $7 \%$.

\subsection{Viscosity Measurements}

The measurements of the melts viscosity were carried out using a computer-controlled oscillating-cup viscometer (Ref 11). Using the Roscoe equation, the dynamic viscosity has been calculated from the corresponding logarithmic decrement of damping and the period of oscillations. The experiments were performed in argon atmosphere under a negligible excess pressure of about 0.02-0.03 MPa. Each sample of about $30 \mathrm{~g}$ was weighed before and after the measurements, and no loss of mass was observed. Cylindrical graphite crucibles with internal diameter of $14 \mathrm{~mm}$ were used. A homogeneous temperature field up to $0.3 \mathrm{~K}$ in the range of absolute values between the

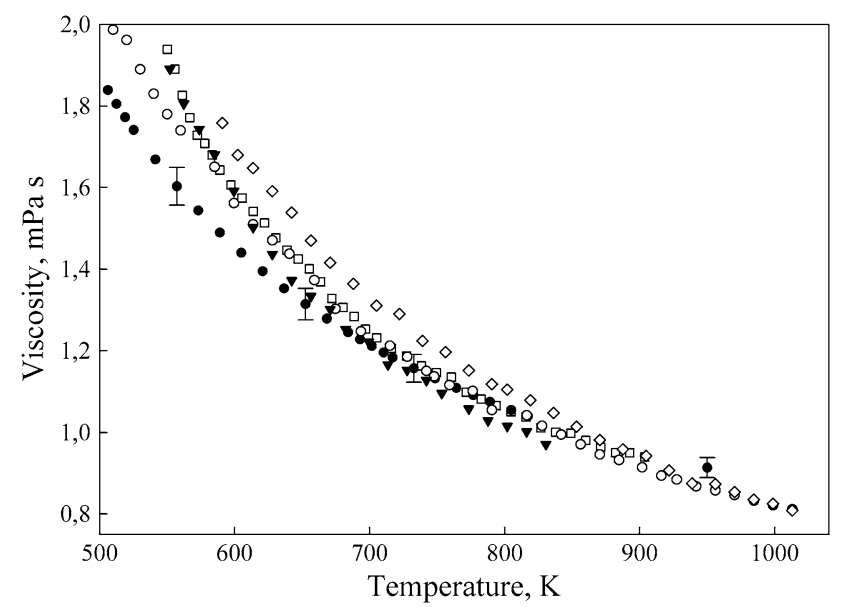

Fig. 4 Viscosity of liquid Ag-Bi-Sn alloys as a function of temperature. $\square \mathrm{Bi}(\operatorname{Ref} 14), \bigcirc \mathrm{Sn}(\operatorname{Ref} 14), \bigcirc \mathrm{Ag}_{3.33} \mathrm{Bi}_{10} \mathrm{Sn}_{86.67}, \boldsymbol{\nabla} \mathrm{Ag}_{6.67-}$ $\mathrm{Bi}_{10} \mathrm{Sn}_{83.33}, \diamond \mathrm{Ag}_{10} \mathrm{Bi}_{10} \mathrm{Sn}_{80}$ melting temperature, $T_{\mathrm{m}}$, and $800 \mathrm{~K}$ was created inside the furnace. The temperature was measured with a WRe-5/20 thermocouple arranged just below the crucible. The viscosity was determined with the accuracy of about $3 \%$.

\section{Results and Discussion}

\subsection{Electrical Conductivity and Thermoelectric Power}

The alloys were heated and cooled several times with different rates, but the change of the rate did not affect noticeably the electrical conductivity behavior. The electrical conductivity of all Ag-Bi-Sn alloys in the solid state decreases gradually with heating according to the linear law (see Fig. 1). A good agreement between heating and cooling curves has been observed. Heating as well as cooling is accompanied by almost linear changes in the electrical properties and the temperature dependence of $\sigma(T)$ can be well fitted by linear functions of type:

$\sigma(T)=\sigma_{\mathrm{R}}-\frac{d \sigma}{d T} T$

where $\sigma_{\mathrm{R}}$ is a conductivity at $300 \mathrm{~K}$ and $\frac{d \sigma}{d T}$ is a temperature coefficient of conductivity.

Reaching a specific temperature $T_{\mathrm{L}}$ close to the value of the liquidus temperature for each composition a deviation from linearity takes place indicating transition to the meltingsolidification region. In the high-temperature range of the liquid state the electrical conductivity behavior is also linear and can be fitted by a similar function

$\sigma(T)=\sigma_{\mathrm{L}}-\frac{d \sigma}{d T} T$

where $\sigma_{\mathrm{L}}$ is a conductivity at the temperature $T_{\mathrm{L}}$, when the sample became completely molten. A scattering of the electrical conductivity data $\sigma(T)$ of the investigated alloys in the liquid state is more pronounced than in solids. The electrical conductivity of all studied melts decreases gradually with heating.

Table 1 gives the parameters of linear fits for the experimental data plotted in Fig. 1. As seen, the electrical conductivity at room temperature increases mildly with increasing Ag content while the changes of the temperature coefficient of conductivity are negligible.

The experimental temperature dependences of the thermoelectric power $S(T)$ of the samples in liquid state are presented in Fig. 2. The thermoelectric power of molten $\mathrm{Sn}$ is about -1 to $-2 \mu \mathrm{V} / \mathrm{K}$ and remains practically constant over the whole studied temperature range.

Table 1 The temperature dependences of the electrical conductivity for the solid ribbons and liquid bulks: linear fits to the experimental data plotted in Fig. 2

\begin{tabular}{|c|c|c|c|c|}
\hline \multirow[b]{2}{*}{ Alloy composition } & \multicolumn{2}{|c|}{ Solid } & \multicolumn{2}{|c|}{ Liquid } \\
\hline & $\sigma_{\mathrm{R}}, \Omega^{-1} \mathrm{~cm}^{-1}$ & $d \lambda / d T, \Omega^{-1} \mathrm{~cm}^{-1} \mathrm{~K}^{-1}$ & $\sigma_{\mathrm{L}}, \Omega^{-1} \mathrm{~cm}^{-1}$ & $d \lambda / d T, \Omega^{-1} \mathrm{~cm}^{-1} \mathrm{~K}^{-1}$ \\
\hline $\mathrm{Ag}_{3.33} \mathrm{Bi}_{10} \mathrm{Sn}_{86.67}$ & 47,500 & $88(300-430 \mathrm{~K})$ & 16,600 & $8.48(510-870 \mathrm{~K})$ \\
\hline $\mathrm{Ag}_{4.67} \mathrm{Bi}_{10} \mathrm{Sn}_{85.33}$ & 49,300 & $86(300-435 \mathrm{~K})$ & 16,820 & $7.23(518-880 \mathrm{~K})$ \\
\hline $\mathrm{Ag}_{6.67} \mathrm{Bi}_{10} \mathrm{Sn}_{83.33}$ & 51,860 & $101(300-445 \mathrm{~K})$ & 17,260 & $6.63(552-870 \mathrm{~K})$ \\
\hline $\mathrm{Ag}_{8.33} \mathrm{Bi}_{10} \mathrm{Sn}_{81.67}$ & 53,220 & $94(300-452 \mathrm{~K})$ & 17,730 & $6.71(581-880 \mathrm{~K})$ \\
\hline $\mathrm{Ag}_{10} \mathrm{Bi}_{10} \mathrm{Sn}_{80}$ & 55,000 & $91(300-440 \mathrm{~K})$ & 18,740 & $5.9(590-890 \mathrm{~K})$ \\
\hline
\end{tabular}


The thermoelectric power of investigated Ag-Bi-Sn liquid alloys is kept at the level of -2 to $-4 \mu \mathrm{V} / \mathrm{K}$ and remains nearly constant with a further heating. An increase of the Ag content has no noticeable influence on the absolute $S(T)$ values.

\subsection{Thermal Conductivity}

The temperature dependence of the thermal conductivity, $\lambda(T)$, was measured for liquid Ag-Bi-Sn alloys up to $750 \mathrm{~K}$. As seen in Fig. 3, the $\lambda(T)$ dependence could be well described by the linear equation:

$\lambda=\lambda_{\mathrm{L}}+\frac{d \lambda}{d T} \times\left(T-T_{\mathrm{L}}\right)$

where $\lambda_{\mathrm{L}}(T)$ is the thermal conductivity (in $\mathrm{W} \mathrm{m}^{-1} \mathrm{~K}^{-1}$ ) at the temperature $T_{\mathrm{L}}$ and $\frac{d \lambda}{d T}$ is the temperature coefficient of the thermal conductivity.

The parameters of the linear fits are specified in Table 2. As seen from Fig. 3, the thermal conductivity increases during heating for all investigated alloy melts according to Eq 3 . The absolute thermal conductivity values as well as their temperature dependences suggest a prevalence of the electron heat transfer. These values also prove rather strong gas degeneracy (Ref 12). In this case the Wiedemann-Franz-Lorenz law (WFL) can be used and the Lorenz number can be determined. Our calculations reveal that the Lorenz number is constant in the investigated temperature range and it is very close to its theoretical (Sommerfeld) value of $2.445 \times 10^{-8} \mathrm{~W} \mathrm{~K}^{-2}$.

As shown in Fig. 3, the experimental thermal conductivity results are consistent with the values calculated from our electrical conductivity data (dashed lines). They are systematically lower, however, within the measurement uncertainty (shown by error bars in Fig. 3).

\subsection{Viscosity}

The dynamic viscosity, $\eta(T)$, of the ternary Ag-Bi-Sn melts was measured during heating and cooling over a wide temperature range above the liquidus. All samples were subjected to at least two heating-cooling cycles. Several experiments with different samples of the same composition revealed good reproducibility of the results. The dynamic viscosity as a function of temperature for the binary alloys is presented in Fig. 4 together with data for pure tin and bismuth.

Although the viscosity of liquid $\mathrm{Sn}$ and $\mathrm{Bi}$ has been studied repeatedly, the viscosity data reported in the literature show a wide scatter. The data available for these elements as well as the summary of different models and viscosity-temperature relations are collected in (Ref 13).

Table 2 Parameters of the linear fits $\lambda=\lambda_{0}+d \lambda / d T$ $\left(T-T_{L}\right)$ to the experimental thermal conductivity

\begin{tabular}{|c|c|c|c|}
\hline Alloy composition & $T_{\mathbf{L}}, \mathbf{K}$ & $\lambda_{0}, \mathrm{~W} \mathrm{~m}^{-1} \mathrm{~K}^{-1}$ & $d \lambda / d T, \mathrm{~W} \mathrm{~m} \mathbf{m}^{-1} \mathrm{~K}^{-2}$ \\
\hline $\mathrm{Ag}_{3.33} \mathrm{Bi}_{10} \mathrm{Sn}_{86.67}$ & 510 & 19.6 & 0.024 \\
\hline $\mathrm{Ag}_{4.67} \mathrm{Bi}_{10} \mathrm{Sn}_{85.33}$ & 518 & 20.21 & 0.021 \\
\hline $\mathrm{Ag}_{6.67} \mathrm{Bi}_{10} \mathrm{Sn}_{83.33}$ & 552 & 22.34 & 0.027 \\
\hline $\mathrm{Ag}_{8.33} \mathrm{Bi}_{10} \mathrm{Sn}_{81.67}$ & 581 & 23.63 & 0.031 \\
\hline $\mathrm{Ag}_{10} \mathrm{Bi}_{10} \mathrm{Sn}_{80}$ & 590 & 25.57 & 0.035 \\
\hline
\end{tabular}

As reported in (Ref 14), cooling of the pure Sn and Bi melts is accompanied by an increase of the viscosity according to an Arrhenius-type empirical equation:

$\eta(T)=\eta_{0} \exp \left(\frac{E_{A}}{R T}\right)$,

where $\eta_{0}$ is a constant (mPass), $R$ is the gas constant $\left(\mathrm{J} \mathrm{mol}^{-1} \mathrm{~K}^{-1}\right), T$ is the absolute temperature $(\mathrm{K}), E_{\mathrm{A}}$ is the viscous flow activation energy $\left(\mathrm{J} \mathrm{mol}^{-1}\right)$. Table 3 gives the parameters of exponential fits for the experimental data plotted in Fig. 4.

As seen from Fig. 4, the viscosities of both elements almost coincide in the high temperature region above approx. $700 \mathrm{~K}$. Approaching the liquidus, the viscosity curve of $\mathrm{Bi}$ becomes steeper than that of Sn. It should be noted that the viscosity as one of the most structurally sensitive property does not reveal any peculiarity and exhibits a smooth exponential variation in the entire temperature range all the way down to $T_{\mathrm{L}}$.

Similar $\eta(T)$ behavior has been revealed also in ternary AgBi-Sn liquid alloys (Fig. 4). Addition of silver results in the increase of viscosity. The absolute viscosity values of all investigated melts are very close to the viscosity of $\mathrm{Sn}$ and $\mathrm{Bi}$ in the high temperature region.

Upon cooling the $\eta(T)$ curves of the Ag-Bi-Sn melts becomes steeper and are consistent with $\eta(T)$ of pure Bi within the limits of experimental error. The highest viscosity values have been revealed in the $\mathrm{Ag}_{10} \mathrm{Bi}_{10} \mathrm{Sn}_{80}$ liquid alloy.

\section{Summary}

Several structure-sensitive properties of Ag-Bi-Sn alloys have been measured in the wide temperature interval above the melting point. The electrical and thermal conductivity change linearly with temperature. A gradual change of the properties suggests a gradual structure rearrangement of local short-range orders in the liquid state. The temperature relations could be recommended as input for thermodynamic simulations. The $\mathrm{Ag}-\mathrm{Bi}-\mathrm{Sn}$ ribbons are not brittle. A shape of thin foil/ribbon of all the compositions studied are elastic enough and convenient for joining of large areas with well-defined joint dimensions, prospectively for joining the metallic matrix composites. The substantiated knowledge of the thermophysical properties of the molten alloys is essential for the development of materials with beneficial structural properties and opens prospects for wide applications, for instance in the electronic industry.

Table 3 Parameters of the exponential fits of $\mathrm{Eq} 4$ to the experimental viscosity data

\begin{tabular}{|c|c|c|}
\hline Alloy composition & $\eta_{0}, \mathrm{mPa} s$ & $E_{\mathrm{A}}, \mathrm{kJ} \mathrm{mol}^{-1}$ \\
\hline $\mathrm{Sn}$ & 0.41 & 6.30 \\
\hline $\mathrm{Bi}$ & 0.296 & 8.45 \\
\hline $\mathrm{Ag}_{3.33} \mathrm{Bi}_{10} \mathrm{Sn}_{86.67}$ & 0.328 & 7.75 \\
\hline $\mathrm{Ag}_{4.67} \mathrm{Bi}_{10} \mathrm{Sn}_{85.33}$ & 0.273 & 7.93 \\
\hline $\mathrm{Ag}_{6.67} \mathrm{Bi}_{10} \mathrm{Sn}_{83.33}$ & 0.251 & 9.20 \\
\hline $\mathrm{Ag}_{8.33} \mathrm{Bi}_{10} \mathrm{Sn}_{81.67}$ & 0.285 & 9.12 \\
\hline $\mathrm{Ag}_{10} \mathrm{Bi}_{10} \mathrm{Sn}_{80}$ & 0.284 & 8.98 \\
\hline
\end{tabular}




\section{Acknowledgments}

This work was carried out within the framework of the COST Action MP0602, joint Slovak-Ukrainian project APVV-SK-UA0043-09, projects APVV-0102-07 and VEGA 2/0111/11 and supported by the National Scholarship Programme of the Slovak Republic (Minerva) and the Fundamental Researches State Fund of Ukraine (projects F28-255, F28-329).

\section{References}

1. WEEE and RoHS Directives, Official Journal of the European Union, 2003, L37, p 19

2. Handbook of Properties of SAC Solders and Joints, Vol 2, C. Schmetterer, H. Ipser, J. Pearce (Eds.), ELFNET - COST 531 LeadFree Solders, COST Office, Brussels, 2008 (ISBN 978-80-86292-267). http://www.univie.ac.at/cost531

3. M. Abtew and G. Selvaduray, Lead-Free Solders in Microelectronics, Mater. Sci. Eng. R, 2000, 27, p 95-141

4. F. Gayle, G. Becka, J. Badgett, G. Whitten, T. Pan, A. Grusd, B. Bauer, R. Lathrop, J. Slattery, I. Anderson, J. Foley, A. Gickler, D. Napp, J. Mather, and C. Olson, High Temperature Lead-Free Solder for Microelectronics, J. Miner. Met. Mater. Soc., 2001, 53, p 17-21
5. J.-M. Song, H.-Y. Chuang, and Z.-M. Wu, Interfacial Reactions Between Bi-Ag High-Temperature Solders and Metallic Substrates, J. Electron. Mater., 2006, 35, p 1041-1049

6. P.T. Vianco and J.A. Rejent, Properties of Ternary Sn-Ag-Bi Solder Alloys: Part I-Thermal Properties and Microstructural Analysis, J. Electron. Mater., 1999, 28, p 1127-1137

7. P.T. Vianco and J.A. Rejent, Properties of Ternary Sn-Ag-Bi Solder Alloys: Part II-Wettability and Mechanical Properties Analyses, J. Electron. Mater., 1999, 28, p 1138-1143

8. K.-W. Moon, W.J. Boettinger, U.R. Kattner, C.A. Handwerker, and D.$\mathrm{J}$. Lee, The Effect of $\mathrm{Pb}$ Contamination on the Solidification Behavior of Sn-Bi Solders, J. Electron. Mater., 2001, 30, p 45-52

9. Yu Plevachuk and V. Sklyarchuk, Electrophysical Measurements for Strongly Aggressive Liquid Semiconductors, Meas. Sci. Technol., 2001, 12, p 23-26

10. V. Sklyarchuk and Yu Plevachuk, A Modified Steady State Apparatus for Thermal Conductivity Measurements for Liquid Metals and Semiconductors, Meas. Sci. Technol., 2005, 16, p 467-471

11. S. Mudry, V. Sklyarchuk, and A. Yakymovych, Influence of Doping with Ni on Viscosity of Liquid Al, J. Phys. Stud., 2008, 12, p 1601-1605

12. J.M. Ziman, The Physics of Metals, Chapters 5, 6, University Press, Cambridge, 1969

13. R.P. Chhabra and D.K. Sheth, Viscosity of molten metals and its temperature dependence, Z. Metallkd., 1990, 81, p 264-271

14. Yu Plevachuk, V. Sklyarchuk, G. Gerbeth, and S. Eckert, Thermophysical Properties of Liquid Tin-Bismuth Alloys, Int. J. Mater. Res., 2010, 101, p 839-844 